\title{
Prevalence and factors associated with undernutrition and anaemia among school children in Durbete Town, northwest Ethiopia
}

\author{
Tilahun Alelign ${ }^{1,2}$, Abraham Degarege $^{3,4^{*}}$ and Berhanu Erko ${ }^{3}$
}

\begin{abstract}
Background: Information about risk factors of undernutrition and anaemia is useful to design appropriate strategies to control the health problems. In this study, the prevalence and factors associated with undernutrition and anaemia were assessed among school children in Abchikeli and Ayalew Mekonnen Elementary Schools, northwest Ethiopia, in February and March 2010.
\end{abstract}

Methods: A cross-sectional study was carried out among 384 school children. Stool samples were examined using single Kato-Katz slide and nutritional status was determined using anthropometry technique. A pre-tested standardized questionnaire was used to gather information on the socio-demographic and the socio-economic status of the school children. Multivariate logistic regression analysis was used to quantify the association of intestinal helminth infection and socio-demographic and socio-economic factors with undernutrition and anaemia.

Results: Out of 384 children examined, $32.3 \%$ were undernourished (27.1\% underweight and $11.2 \%$ stunted) and $10.7 \%$ were anaemic. The odds of stunting were approximately seven times higher in children of ages 10 to 14 [Adjusted Odds Ratio (AOR) $=6.93,95 \% \mathrm{Cl}=2.60,18.46$ ] and 2.5 times higher in males $[\mathrm{AOR}=2.50,95 \% \mathrm{Cl}=1.24,5.07$ ] than children of ages 5 to 9 and females, respectively. The odds of underweight was three times higher in children who did not wash their hands before eating compared to those who did wash their hands $[A O R=3.13,95 \% \mathrm{Cl}=1.19$, 8.17]. The chance of anaemia was nine times higher in children who were infected with hookworms compared to those who were not infected with any helminth species $[A O R=8.87,95 \% \mathrm{Cl}=2.28,34.58]$. The odds of being undernourished and anemic were similar among children with different socio-economic status.

Conclusions: Undernutrition and anaemia are public health problems of school-age children in Durbete Town. Health education and provision of additional food supplements would be important to reduce the problem of undernutrition among school-age children in the town. Deworming of children in the town would also have additional impact on reducing the level of anaemia.

Keywords: Undernutrition, Anaemia, School children, Northwest Ethiopia

\section{Background}

Undernutrition and anaemia are common public health problems among people in the developing regions. These diseases are particularly prevalent in children. About $25.4 \%$ of school age children in the world are anaemic [1]. Closer to $90 \%$ of undernourished children under-

\footnotetext{
* Correspondence: abrahamdegarege@yahoo.com

${ }^{3}$ Aklilu Lemma Institute of Pathobiology, Addis Ababa University, P.O. Box 1176 Addis Ababa, Ethiopia

${ }^{4}$ Department of Epidemiology, Robert Stempel College of Public Health and Social Work, Florida International University, Miami, FL, USA

Full list of author information is available at the end of the article
}

five years of age in the globe live in developing regions [2] and $40 \%$ of school age children living in developing regions are anaemic [1]. Undernutrition and anaemia affect physical and mental development and immunity, increasing susceptibility of cases to infection and death $[3,4]$. Undernutrition is responsible for the death of one-third of children (7.6 million children) in the globe every year [5].

Poverty, illiteracy, poor diet practice, genetic abnormalities, digestive difficulties, absorption problems and intestinal helminth infection are major risk factors associated 
with anaemia and undernutrition in children [6-10]. Due to the low socio-economic and sanitation conditions prevailing in Ethiopia, undernutrition and anaemia are common problems of citizens (particularly children) of the country. The country remains one of the most undernourished populations in the world [11]. About 44, 29 and $10 \%$ of children under five years of age in Ethiopia were stunted, underweight and wasted, respectively [12]. Although the major risk factors of undernutrition and anaemia have been previously reported in different regions, the specific causes may vary with localities and time. In addition, causes of anaemia and undernutrition in developing regions are heterogeneous and complex. Hence, current information about risk factors of the problems for each region is helpful to design integrated, timely and appropriate strategies to effectively control the diseases. In this study, the prevalence and factors associated with undernutrition and anaemia were assessed among school children in Abchikeli and Ayalew Mekonnen Elementary Schools, northwest Ethiopia, in February and March 2010.

\section{Methods}

\section{Study area and population}

The study was conducted among school children (age: 5 to 15 years) in Abchikeli and Ayalew Mekonen Elementary Schools located in Durbete Town, northwest Ethiopia, in February and March 2010. The town is divided into 2 kebeles (the smallest administrative units). A total of 17,497 people live in the area (7781 males and $9716 \mathrm{fe}-$ males). According to the health center files, worm infections are the second (next to malaria) causes for visiting health centers for communities living in the town. The altitude of the town is 1500 masl. The mean annual temperature and annual rain fall ranges from 9 to $25{ }^{\circ} \mathrm{C}$ and $1400 \mathrm{~mm}$ to $1594 \mathrm{~mm}$, respectively. The dominant soil type of the study area is brown and black loamy soil. The majority of the population of the town are engaged in mixed agricultural activities. Using multistage random sampling, a total of 384 (247 from Abchikeli and 137 from Ayalew Mekonnen Elementary Schools) school children were proportionally selected based on the size of the students of age 5 to 15 in each school enrolled in the study.

\section{Socio-demographic and socio-economic}

Information about age, sex, education status of parents, grade level of the children, house floor nature, presence of latrine, hand washing habit before eating, drinking water source, place of residence and religious status of children was collected using a questionnaire. A pre-tested structured questionnaire was constructed in English and translated into Amharic. Then, the children were interviewed in Amharic.

\section{Stool collection and examination}

The school children were provided with small plastic sheets and clean wooden applicator stick and informed to bring about $5 \mathrm{mg}$ stool sample. The samples were then processed using Kato-Katz method and examined microscopically for ova of intestinal helminths [13]. Egg counts for hookworm were made on the spot within 30 to $45 \mathrm{~min}$ of slide preparation, whereas the specimens were quantitatively examined for the eggs of A. lumbricoides and T. trichiura within one week of specimen collection at the laboratory of Aklilu Lemma Institute of Pathobiology, Addis Ababa University. Eggs counted for each species of helminth were multiplied by 24 to estimate the number of eggs in a gram of stool and infection intensity was determined accordingly [14].

\section{Nutritional status}

Weight and height were measured using a digital portable weighing calibrated SECA scale. The school children were weighed wearing light clothes (school uniforms) without shoes. The calibrated SECA balance scale has intervals/ sensitivity of $0.1 \mathrm{~kg}$ and $0.1 \mathrm{~cm}$ precision. Weighing scale was calibrated to zero before taking every measurement. Classification of the nutritional status of the children was made according to the WHO Growth Standards. Children were considered undernourished when they were either stunted ( $Z$ of height for age less than -2 ) or underweight ( $Z$ of body mass index for age less than -2 ) [15].

\section{Haemoglobin level determination}

Blood samples from each child were collected by finger pricking after rubbing the finger-tip with sterile cotton (immersed in alcohol), and pricking it with a sterile disposable lancet. A drop of blood was then allowed to enter the optical window of the microcuvette through capillary action. The microcuvett was placed into the cuvett holder of a hemocue spectrophotometer (Hemocue HB 201 analyzer) and the concentration of haemoglobin was quantitatively determined in $\mathrm{g} / \mathrm{dl}$. Anaemic status was then determined accordingly. The haemoglobin cut-off levels indicating anemia were below $11.5 \mathrm{~g} / \mathrm{dl}$ for children in the 5-11 years age group and below $12.0 \mathrm{~g} / \mathrm{dl}$ for children in the 12-14 years age group [16].

\section{Data analysis}

The data were entered, cleaned and checked using Excel 2007 and analysis was performed using STATA (version 10, Stata Corporation, College Station, Texas, USA). Proportions were used to describe the prevalence of intestinal helminth infections, stunting, underweight and anaemia. Z-test of proportions was used to test the difference in the prevalence of stunting, underweight and undernutrition between different age and sex groups. Multivariate logistic regression analysis was used to 
measure the strength of association of socio-economicand socio-demographic factors and intestinal helminth infections with undernutrition and anaemia. Ninety five percent confidence interval (CI) was calculated for the odds ratio values. Values were considered significant when $\mathrm{P}<0.05$.

\section{Ethical considerations}

Ethical clearance was obtained from the Ethical Clearance Committee of the Department of Microbial, Cellular and Molecular Biology, College of Natural Sciences, Addis Ababa University. Permission to conduct the study was also obtained from Debub Achefer District Health Offices, educational authorities and school principals. The samples were collected from children who gave their assent and whose parents/guardians signed the written informed consent. All children who had intestinal helminth infections were treated with an appropriate dose of $500 \mathrm{mg}$ mebendazole.

\section{Results}

A total of 403 children were contacted of whom 384 brought stool samples and responded to the questionnaire. Of a total of 384 study participants examined, $32.3 \%$ were undernourished and $10.7 \%$ were anaemic (Table 1). About $27.1 \%$ of the children were underweight while $11.2 \%$ were stunted. The prevalence of stunting was significantly higher in males $(\mathrm{P}=0.01)$ and children of ages 10 to 15 years $(\mathrm{P}<0.01)$ compared to females and children of ages 5 to 9 years (Table 2), respectively. The difference in the prevalence of anaemia was not significant between sexes $(P=0.64)$ and age groups $(P=0.53)$.

Intestinal helminth infection, undernutrition and anaemia The odds of stunting was seven times higher in children of ages 10 to 14 [Adjusted Odds Ratio $(\mathrm{AOR})=6.93$, $95 \% \mathrm{CI}=2.60,18.46]$ and 2.5 times higher in males [AOR $=2.50,95 \% \mathrm{CI}=1.24,5.07]$ than children of ages 5 to 9 and females, respectively. The chance of anaemia was approximately nine times higher in children who were infected with hookworm compared to those who were not infected with helminths $[\mathrm{AOR}=8.87,95 \% \mathrm{CI}=$ $2.28,34.58$ ] (Table 3). However, the difference in the prevalence of underweight was not significant between males and females and children of ages 5 to 9 and 10 to 14 years. Similarly, the difference in the prevalence of underweight and stunting were not significant between children who were infected and those not infected with intestinal helminths.

\section{Association of socio-economic and socio-demographic} factors with undernutrition and anaemia

The odds of underweight was three times higher in children who did not wash their hands before eating
Table 1 Characteristics of children in Abchikeli and Ayalew Mekonnen elementary, northwest Ethiopia, February and March 2010

\begin{tabular}{|c|c|c|c|}
\hline Variables & Categories & Frequency & Percent \\
\hline \multirow[t]{2}{*}{ Age in years } & $5-9$ & 175 & 45.6 \\
\hline & $10-14$ & 209 & 54.4 \\
\hline \multirow[t]{2}{*}{ Sex } & Male & 172 & 44.8 \\
\hline & Female & 212 & 55.2 \\
\hline \multirow[t]{2}{*}{ Helminth infection } & Yes & 211 & 54.9 \\
\hline & No & 173 & 45.1 \\
\hline \multirow[t]{2}{*}{ Nutrition status } & Undernourished & 124 & 67.7 \\
\hline & Normal & 264 & 32.3 \\
\hline \multirow[t]{2}{*}{ Anaemic status } & Anaemic & 41 & 10.7 \\
\hline & Not anaemic & 343 & 89.3 \\
\hline Family & 1 to 3 & 207 & 53.9 \\
\hline \multirow[t]{2}{*}{ Size } & $4-6$ & 123 & 32.0 \\
\hline & $\geq 7$ & 54 & 14.1 \\
\hline Fathers & Literate & 182 & 47.4 \\
\hline education & Illiterate ${ }^{a}$ & 202 & 52.6 \\
\hline Mothers & Literate & 143 & 37.2 \\
\hline education & Illiterate ${ }^{a}$ & 241 & 62.8 \\
\hline Drinking & Tap & 131 & 34.1 \\
\hline water & Well & 148 & 38.5 \\
\hline sources & River/spring & 105 & 27.4 \\
\hline Hand & Yes & 361 & 94.0 \\
\hline Washing habit before eating & No & 23 & 6.0 \\
\hline Shoe & Yes & 86 & 22.4 \\
\hline Wearing & No & 298 & 77.6 \\
\hline Presence & Yes & 151 & 39.2 \\
\hline of latrine & No & 233 & 60.7 \\
\hline House & Cement & 21 & 5.5 \\
\hline Floor & Earthen & 263 & 94.5 \\
\hline \multirow[t]{2}{*}{ Residence } & Urban & 137 & 35.7 \\
\hline & Rural & 247 & 64.3 \\
\hline \multirow[t]{2}{*}{ Grade } & 1 to 3 & 279 & 72.7 \\
\hline & 3 to 6 & 105 & 27.3 \\
\hline \multirow[t]{2}{*}{ Religion } & Christian & 366 & 95.3 \\
\hline & Muslim & 18 & 4.7 \\
\hline
\end{tabular}

lliterate $^{\mathrm{a}}=$ can not read and write

compared to those who did wash their hands [AOR = $3.13,95 \% \mathrm{CI}=1.19,8.17$ ]. However, the odds of underweight and stunting were similar between children with different family size, family education status, drinking water source, shoe wearing habit, living house floor nature, place of residence, latrine usage habit and grade level. Similarly, the chance of developing anaemia was similar between children with different socio-economic status (Table 4). 
Table 2 Prevalence of undernutrition and anaemia among children in Abchikeli and Ayalew Mekonnen Elementary Schools stratified by age and sex, northwest Ethiopia, February and March 2010

\begin{tabular}{|c|c|c|c|c|c|}
\hline Variables & Number examined & $\begin{array}{l}\text { Percent stunted } \\
(\mathrm{HAZ}<-2)\end{array}$ & $\begin{array}{l}\text { Percent underweight } \\
(B A Z<-2 \text { or } W A Z<-2)\end{array}$ & $\begin{array}{l}\text { Percent undernourished } \\
(W A Z<-2 \text { or } \mathrm{HAZ}<-2 \text { or } \mathrm{BAZ}<-2)\end{array}$ & Percent anaemia \\
\hline \multicolumn{6}{|l|}{ Age } \\
\hline $5-9$ & 175 & 4.57 & 30.86 & 31.43 & 7.43 \\
\hline $10-14$ & 209 & 16.75 & 23.92 & 33.01 & 13.4 \\
\hline Total & 384 & 11.2 & 27.1 & 32.3 & 10.7 \\
\hline P-value & & 0.00 & 0.13 & 0.74 & 0.53 \\
\hline \multicolumn{6}{|l|}{ Sex } \\
\hline Females & 212 & 7.6 & 69.81 & 33.02 & 11.32 \\
\hline Males & 172 & 15.7 & 76.74 & 31.4 & 9.9 \\
\hline P-value & & 0.01 & 0.13 & 0.74 & 0.64 \\
\hline
\end{tabular}

WAZ $=$ Z-scores for Weight-for-age- calculated when age from 5 to 10 years

$\mathrm{HAZ}=\mathrm{Z}$-scores for Length/height-for-age- calculated when age from 5 to 15 years

$\mathrm{BAZ}=\mathrm{Z}$-scores for BMI-for-age- calculated when age from 5 to 15 years

\section{Discussion}

A total of 384 children enrolled in Abchikele and Ayalew Mekonnen Elementary Schools were examined and $32.3 \%$ of them were found undernourished $(27.1 \%$ were underweight and $11.2 \%$ were stunted) and $10.7 \%$ were anaemic. Male and older age children were at risk of being stunted and those who did not wash their hands before eating were at risk of being underweight. The chance of being anaemic was higher in children who were infected with hookworm compared to those who were not infected with helminths. However, the prevalence of undernutrition and anaemia were similar between children with different socio-economic status and those who were infected with intestinal helminth and those were not infected.

The prevalence of undernutrition (underweight and/or stunting) in the current study was similar to a recent report among school-age children in Addis Ababa (30.9\%) [17]. The prevalence of underweight found out in the current study is also comparable with the prevalence documented in other regions of Ethiopia [18, 19]. However, some studies documented a higher prevalence of stunting (19.6 to $29.3 \%$ ) [17-20] and undernutrition (underweight and/or stunting) (42 to $46.7 \%$ ) [17, 19, 20] among school-age children in different places of the country. These differences could be due to variations in

Table 3 Association of intestinal helminth infection, sex and age with undernutrition and anaemia among children in in Abchikeli and Ayalew Mekonnen elementary schools, northwest Ethiopia, February and March 2010

\begin{tabular}{|c|c|c|c|c|c|c|c|}
\hline \multirow[b]{2}{*}{ Variables } & \multirow[b]{2}{*}{ Categories } & \multicolumn{2}{|c|}{ Undernutrition } & \multirow[b]{2}{*}{$\mathrm{AOR}^{\mathrm{a}}[95 \% \mathrm{Cl}]$} & \multicolumn{2}{|c|}{ Anaemia } & \multirow[b]{2}{*}{$\mathrm{AOR}^{\mathrm{a}}[95 \% \mathrm{Cl}]$} \\
\hline & & Yes & No & & Yes & $\mathrm{No}$ & \\
\hline \multirow[t]{8}{*}{ Helminth infection } & Non-infected & 55 & 118 & - & 3 & 170 & - \\
\hline & A. lumbricoides & 13 & 13 & $2.16[0.85,5.53]$ & 0 & 26 & NA \\
\hline & Hookworm & 44 & 101 & $1.42[0.80,2.52]$ & 23 & 122 & $8.87[2.28,34.58]$ \\
\hline & T. trichiura & 0 & 5 & NA & 0 & 5 & NA \\
\hline & Any & 69 & 142 & $1.28[0.79,2.09]$ & 38 & 173 & $10.65[2.96,38.39]$ \\
\hline & Single & 57 & 119 & $1.41[0.85,2.33]$ & 23 & 153 & $8.11[2.20,29.88]$ \\
\hline & Double & 10 & 23 & $0.53[0.17,1.65]$ & 15 & 18 & $43.56[8.42,225.55]$ \\
\hline & Triple & 2 & 0 & NA & 0 & 2 & NA \\
\hline \multirow[t]{2}{*}{ Age in years } & $5-9$ & 55 & 120 & - & 13 & 162 & - \\
\hline & $10-14$ & 69 & 140 & $1.36[0.76,2.43]$ & 28 & 181 & $0.61[0.22,1.71]$ \\
\hline \multirow[t]{2}{*}{ Sex } & Male & 54 & 118 & - & 17 & 155 & - \\
\hline & Female & 70 & 142 & $1.17[0.73,1.86]$ & 24 & 188 & $1.06[0.49,2.26]$ \\
\hline
\end{tabular}


Table 4 Association of socioe-conomic and socio-demographic factors factors with undernutrition and anaemia among children in Abchikeli and Ayalew Mekonnen Elementary Schools, northwest Ethiopia, February and March 2010

\begin{tabular}{|c|c|c|c|c|c|c|c|}
\hline \multirow[b]{2}{*}{ Variables } & \multirow[b]{2}{*}{ Categories } & \multicolumn{2}{|c|}{ Undernutrition } & \multirow[b]{2}{*}{ AOR $[95 \% \mathrm{Cl}]^{a}$} & \multicolumn{2}{|c|}{ Anaemia } & \multirow[b]{2}{*}{ AOR $[95 \% \mathrm{Cl}]^{\mathrm{a}}$} \\
\hline & & $\overline{\text { Yes }}$ & No & & $\overline{Y e s}$ & $\overline{\mathrm{No}}$ & \\
\hline Family & 1 to 3 & 74 & 133 & - & 20 & 187 & - \\
\hline \multirow[t]{2}{*}{ Size } & $4-6$ & 33 & 90 & $0.78[0.45,1.35]$ & 13 & 110 & $0.61[0.25,1.48]$ \\
\hline & $\geq 7$ & 17 & 37 & $0.94[0.44,1.99]$ & 8 & 146 & $0.93[0.32,2.72]$ \\
\hline Fathers & Literate & 66 & 116 & - & 17 & 165 & - \\
\hline education & Illiterate ${ }^{b}$ & 58 & 144 & $0.88[0.39,1.99]$ & 24 & 178 & $0.90[0.29,2.75]$ \\
\hline Mothers & Literate & 55 & 88 & - & 11 & 132 & - \\
\hline education & Illiterate ${ }^{b}$ & 69 & 172 & $1.33[0.55,3.22]$ & 30 & 211 & $0.87[0.22,345]$ \\
\hline Drinking & Tap & 55 & 76 & - & 5 & 126 & - \\
\hline water & Well & 42 & 106 & $0.64[0.21,1.97]$ & 26 & 122 & $0.91[0.05,15.33$ \\
\hline sources & River/spring & 27 & 78 & $0.27[0.02,3.85]$ & 10 & 95 & $0.68[0.02,23.08]$ \\
\hline Hand & Yes & 113 & 248 & - & 33 & 328 & - \\
\hline washing \pm & No & 11 & 12 & $2.62[1.02,6.72]$ & 8 & 15 & $2.73[0.90,8.24]$ \\
\hline Shoe & Yes & 34 & 52 & - & 1 & 85 & - \\
\hline Wearing & No & 90 & 208 & $1.09[0.52,2.29]$ & 40 & 258 & $5.91[0.41,85.95]$ \\
\hline Presence & Yes & 62 & 89 & - & 8 & 143 & - \\
\hline of latrine & No & 62 & 171 & $0.60[0.22,1.64]$ & 33 & 200 & $0.30[0.04,2.07]$ \\
\hline House & Cement & 11 & 10 & - & 2 & 19 & - \\
\hline Floor & Earthen & 113 & 250 & $1.79[0.54,5.96]$ & 39 & 324 & $4.13[0.09,195.52]$ \\
\hline \multirow[t]{2}{*}{ Residence } & Urban & 57 & 80 & - & 6 & 131 & - \\
\hline & Rural & 67 & 180 & $1.19[0.33,4.36]$ & 63 & 212 & $0.11[0.00,3.03]$ \\
\hline \multirow[t]{2}{*}{ Grade } & 1 to 3 & 89 & 190 & - & 24 & 255 & - \\
\hline & 4 to 6 & 35 & 70 & $1.57[0.81,3.07]$ & 17 & 88 & $2.23[0.82,6.10]$ \\
\hline \multirow[t]{2}{*}{ Religion } & Christian & 117 & 249 & - & 39 & 327 & - \\
\hline & Muslim & 7 & 11 & $0.40[0.09,1.82]$ & 2 & 16 & $0.61[0.02,15.63]$ \\
\hline
\end{tabular}

$\mathrm{AOR}^{\mathrm{a}}$ (adjusted odds ratio): adjusted for age, sex, helminth infection, education status of parents, grade level of the children, house floor nature, presence of latrine, hand washing habit before eating, drinking water source, place of residence and religious status: based on two (for anaemia and undernutrition) independent multivariable regression models

Illiterate ${ }^{\text {b }}$ Can not read and write

Hand washing \pm : hand washing habit before eating

the factors predisposing to underweight and stunting in the different regions of Ethiopia. Stunting is chronic and associated with long term factors; howevere, being underweight is due to current and acute or chronic inadequate nutrition.

The prevalence of anaemia among school-age children in the current study is mild. However, a relatively high prevalence of anaemia (27.6 to $37.6 \%$ ) was observed among school-age children in a different regions of Ethiopia [21-23]. The etiologic agents of anaemia are different and could vary from place to place [16]. This may contribute to the differences in the prevalence of anaemia among school-age children in different regions of the country.

Male children of ages 10 to 14 years were at higher risk of being stunted. Similar previous studies also reported a higher prevalence of stunting in males than in females [18, 24-27] and in children of ages 10 to 14 years compared to those of ages 5 to 9 years [28-30]. These sex and age biases in the prevalence of stunting in the area could be related to community specific cultures. In the region, male children are usually more mobile and undertake different playing activities (e.g. sport) that make them loss grater energy from their body. On the other hand, females are usually give more attention to their personal hygiene than males, are less mobile in their behavior and stay at home, have more access to different food staff. As a result, females will be less vulnerable to undernutrition compared to males. Particularly, the physical activities are frequently practiced by older age children. On the other hand, the habit of not washing hands before eating among children was associated with a greater prevalence of underweight rather than stunting. Unlike stunting, which shows cumulative effects 
starting from a past period, being underweight is acute, indicating current nutritional status of children. Not washing hands before eating may cause acute bacterial or parasitic infection that would lead to diarrhea or malabsorption problems and acute undernutrition.

Hookworm infection was independently associated with an increased risk of anaemia, as previously reported by many studies [31, 32]. However, the number of children infected with $A$. lumbrcoides and T. trichiura alone were too small to make valid statistical tests regarding the impact of these infections on anaemia and undernutrition. On the other hand, Soil Transmitted Helminths infection in general was not associated with undernutrition. This is in contrast to some previous studies [32-34]. The intensity of the majority of infections in the current study was light. As a result, the infections may not have significant impact on the nutritional status of the children.

Although previous studies linked low education status of mothers/fathers, drinking unprotected water, defecating in open fields, living in rural area and not wearing of shoes with undernutrition [35-39] and anaemia [40-42], similar associations were not observed in the present study. Other studies also reported that the aforementioned socio-economic factors do not increase the risk of undernutrition or anaemia $[43,44]$. Different communities have different lifestyles, cultures, religions and environmental conditions. As a result, risk factors of undernutrition and anaemia may not be similar in all areas.

The use of single Kato Katz slide was a limitation in the present study because it might have underestimated the prevalence and intensity of infection in the study population. In addition, the cross-sectional nature of the study design hampers making conclusive conclusions regarding the impact of the socio economic factors and intestinal helminth infection on anaemia and undernutrition. Further community based longitudinal studies would be helpful to evaluate whether Soil Transmitted Helminths infection and poor socioeconomic, low education, poor sanitation status could lead to undernutrition and anaemia in children and adult among the communities in Durbete Town, North west Ethiopia.

\section{Conclusions}

Undernutrition and anaemia are public health problems of school age children in Durbete town. Being male, age between 10 and 14 years and not washing hands before eating increases the risk of undernutrition. Hookworm infection was associated with a higher risk of anaemia. Health education and provision of additional food supplements could be important to reduce the problem of undernutrition among school age children in the town. Deworming of school age children in the town would also have additional impact on reducing the prevalence of anaemia among school age children living in Durbete town.
Competing interests

The authors declare that they have no competing interests.

\section{Authors' contributions}

TA and BE: conceived the project idea and designed the study protocol; TA: collected the data; AD: analyzed the data and drafted the manuscript. All authors read and approved the final manuscript.

\section{Acknowledgements}

This study received financial support from Faculty of Science, Addis Ababa University. We would like to thank the staffs of Durbete District Heath Center for their cooperation during the study. Our thanks also go to the study participants for their cooperation and taking part in the study.

\section{Author details}

${ }^{1}$ Department of Microbial, Cellular and Molecular Biology, College of Natural Sciences, Addis Ababa University, P.O. Box 1176, Addis Ababa, Ethiopia. ${ }^{2}$ Department of Biology, Debre Birhan University, Debre Birhan, Ethiopia. ${ }^{3}$ Aklilu Lemma Institute of Pathobiology, Addis Ababa University, P.O. Box 1176 Addis Ababa, Ethiopia. ${ }^{4}$ Department of Epidemiology, Robert Stempel College of Public Health and Social Work, Florida International University, Miami, FL, USA.

Received: 25 November 2014 Accepted: 17 June 2015

Published online: 10 August 2015

\section{References}

1. Benoist B, McLean E, Cogswell M, Egli I, Wojdyla D. Worldwide prevalence of anaemia 1993-2005. World Health Organization Global Database on Anaemia. Geneva: World Health Organization; 2008. p. 1-55.

2. UNICEF-WHO-The World Bank Joint Child Malnutrition Estimates: Levels and trends in child malnutrition. UNICEF; WHO; The World Bank, 2012. http://www who.int/nutgrowthdb/jme_unicef_who_wb.pdf. Accessed May 8, 2015.

3. Grantham-McGregor S, Ani C. A review of studies on the effect of iron deficiency on cognitive development in children. J Nutr. 2001;131(2):649-66.

4. Nokes C, van den Bosch C, Bundy DAP. The Effects of Iron Deficiency and Anemia on Mental and Motor Performance, Educational Achievement, and Behaviors in Children. An Annotated Bibliography. Washington, DC: INACG and ILSI Press; 1998.

5. World Health Organization. Communicable disease and severe food shortage technical Note. Geneva: WHO; 2010.

6. Bhutta ZA, Ahmed T, Black RE, Cousens S, Dewey K, Giugliani E, et al. What works Interventions for maternal and child under nutrition and survival. Lancet. 2008;371:417-40.

7. Pasricha SR, Biggs BA. Undernutrition among children in South and SouthEast Asia. J Paediatr Child Health. 2010;46:497-503.

8. Black RE, Allen LH, Bhutta ZA, Caulfield LE, de Onis M, Ezzati M, et al. Maternal and child undernutrition: global and regional exposures and health consequences. Lancet. 2008;19(371):243-60.

9. Westergren A, Wann-Hansson C, Börgdal EB, Sjölander J, Strömblad R. Malnutrition prevalence and precision in nutritional care differed in relation to hospital volume - a cross-sectional survey. Nutr J. 2009;8:20.

10. Haidar JA, Pobocik RS. Iron deficiency anemia is not a rare problem among women of reproductive ages in Ethiopia: a community based cross sectional study. BMC Blood Disord. 2009;9:7.

11. Headey DD: An analysis of trends and determinants of child undernutrition in Ethiopia, '2000-2011. International Food Policy Research Institute and Ethiopian Development Research Institute, 2014. Working paper http://ebrary.ifpri.org/ cdm/ref/collection/p15738coll2/id/128896. Accessed May 9, 2015.

12. CSA [Ethiopia] and ICF International. Ethiopia Demographic and Health Survey 2011. Addis Ababa, Ethiopia and Calverton, Maryland, USA: Central Statistical Agency and ICF International; 2012.

13. World Health Organization. Basic Laboratory Methods in Medical Parasitology. Geneva: WHO; 1991.

14. World Health Organization. Prevention and control of schistosomiasis and soil-transmitted helminthiasis. Tech Rep Ser. 2002;912:1-57.

15. World Health Organization. Child Growth Standards: length /height-for-age, weight-for-age, weight-for-length, weight-for height and body mass indexforage. In: Methods and development. Geneva: WHO; 2006.

16. World Health Organization. Iron Deficiency Anaemia: Assessment, Prevention and Control, a Guide for Programme Managers. Geneva: WHO; 2001. 
17. Degarege D, Degarege A, Animut A. Undernutrition and associated risk factors among school age children in Addis Ababa, Ethiopia. BMC Public Health. 2015;15:375.

18. Degarege A, Hailemeskel E, Erko B. Age-related factors influencing the occurrence of undernutrition in northeastern Ethiopia. BMC Public Health. 2015;15:108.

19. Degarege A, Erko B. Association between intestinal helminth infections and underweight among school children in Tikur Wuha Elementary School, Northwestern Ethiopia. J Infect Public Health. 2013;6:125-33.

20. Herrador Z, Sordo L, Gadisa E, Moreno J, Nieto J, Benito A et al. Crosssectional study of malnutrition and associated factors among school aged children in rural and urban settings of Fogera and Libo Kemkem districts, Ethiopia. Plos One. 2014;9(9):e105880.

21. Assefa S, Mossie A, Hamza L. Prevalence and severity of anemia among school children in Jimma Town, Southwest Ethiopia. BMC Hematol. 2014;14:3.

22. Mesfin F, Berhane Y, Worku A. Anemia among Primary School Children in Eastern Ethiopia. PLoS One. 2015;10(4), e0123615.

23. Herrador Z, Sordo L, Gadisa E, Buño A, Gómez-Rioja R, Iturzaeta JM. Micronutrient deficiencies and related factors in school-aged children in Ethiopia: a cross-sectional study in Libo Kemkem and Fogera districts, Amhara Regional State. PLoS One. 2014;9(12), e112858.

24. Svedberg P. Undernutrition in sub-Saharan Africa: is there a gender bias? J Dev Stud. 1990;26:469-86.

25. Wamani H, Astrøm AN, Peterson S, Tumwine JK, Tylleskär T. Boys are more stunted than girls in sub-Saharan Africa: a meta-analysis of 16 demographic and health surveys. BMC Pediatr. 2007;10:7-17.

26. Parraga I. Gender differences in growth of school-age children with schistosomiasis and geohelminth infection. Am J Trop Med Hyg. 2000;55:150-6.

27. Francis L, Kirunda B, Orach CG. Intestinal Helminth Infections and Nutritional Status of Children Attending Elementary Schools in Wakiso District, Central Uganda. Int J Environ Res Public Health. 2012;9:2910-21.

28. Lwambo NJ, Brooker S, Siza JE, Bundy DA, Guyatt H. Age patterns in stunting and anaemia in African schoolchildren: a cross-sectional study in Tanzania. Eur J Clin Nutr. 2000;54:36-40.

29. Genebo T, Girma W, Hadir J, Demmissie T. The association of children's nutritional status to maternal education in Ziggbaboto, Guragie Zone South Ethiopia. Ethiop J Health Dev. 1999;13:55-61.

30. Yimer G. Malnutrition among children in southern Ethiopia: Levels and risk factors. Ethiop J Health Dev. 2000;14(3):283-92.

31. Mwangi TW, Bethony JM, Brooker S. Malaria and helminth interactions in humans: an epidemiological viewpoint. Ann Trop Med Parasitol. 2006:100:551-70.

32. Ulukanligil M, Seyrek A. Anthropometric status, anaemia and intestinal helminthic infections in shantytown and apartment schoolchildren in the Sanliurfa province of Turkey. Europ J Clin Nutr. 2004:58:1056-61.

33. Quihui-Cota L, Valencia ME, Crompton DWT, Phillips S, Hagan P, Diaz-Camacho SP, et al. Prevalence and intensity of intestinal parasitic infections in relation to nutritional status in Mexican schoolchildren. Trans R Soc Trop Med Hyg. 2004;98:653-9.

34. Casapía M, Joseph SA, Núñez C, Rahme E, Gyorkos TW. Parasite risk factors for stunting in grade 5 students in a community of extremem poverty in Peru. Int J Parasitol. 2006;36:741-7.

35. Jayne J, Scrimgeour AG, Polhemus ME, Otieno L, Bovil ME. Dietary and socio-economic correlates of nutritional status in a rural adult Kenyan population. Afr J Food Agric Nut Dev. 2011;11:5035-2.

36. Chagas DC, Silva AA, Batista RF, Simões VM, Lamy ZC. Prevalence and factors associated to malnutrition and excess weight among under five year-olds in the six largest cities of Maranhão. Rev Bras Epidemiol. 2013;16:146-56.

37. Pongou R, Ezzati M, Salomon JA. Household and community socioeconomicand environmental determinants of child nutritional status in Cameroon. BMC Public Heath. 2006;6:98-116.

38. Jardim-Botelho A, Brooker S, Geiger SM, Fleming F, Lopes ACS, Diemert DJ, et al. Age patterns in undernutrition and helminth infection in a rural area of Brazil: associations with ascariasis and hookworm. Trop Med Int Health. 2008;13:458-67.

39. Urke HB, Bull T, Mittelmark MB. Socioeconomic status and chronic child malnutrition: Wealth and maternal education matter more in the Peruvian Andes than nationally. Nutr Res. 2011;31:741-747.

40. Assis AM, Barreto ML, Gomes GSS, Prado MS, Santos NS, Santos LMP, et al. Childhood anemia: prevalence and associated factors in Salvador, Bahia, Brazil. Cad Saude Publica. 2004;20:1633-41.
41. Alaofè $H$, Zee J, Dossa R, O'Brien HT. Education and improved iron intakes for treatment of mild iron-deficiency anemia in adolescent girls in southern Benin. Food Nutr Bull. 2009;30:24-36.

42. Bassam F, AL-ZAIN. Impact of socio-economicconditions and parasitic infection on hemoglobin level among children in Um-unnasser village, Gaza Strip. Turk J Med Sci. 2009;39:53-8.

43. Gutema B, Adissu W, Asress Y, Gedefaw L. Anemia and associated factors among school-age children in Filtu Town, Somali region, Southeast Ethiopia. BMC Hematol. 2014;14:13.

44. Wong HJ, Moy FM, Nair S. Risk factors of malnutrition among preschool children in Terengganu, Malaysia: a case control study. BMC Public Health. $2014 ; 14: 785$

\section{Submit your next manuscript to BioMed Central and take full advantage of:}

- Convenient online submission

- Thorough peer review

- No space constraints or color figure charges

- Immediate publication on acceptance

- Inclusion in PubMed, CAS, Scopus and Google Scholar

- Research which is freely available for redistribution 